\title{
An Intelligent PI Controller-Based Hybrid Series Active Power Filter for Power Quality Improvement
}

\author{
Arjun Baliyan $\mathbb{D}^{1},{ }^{1}$ Majid Jamil, ${ }^{1}$ M. Rizwan $\mathbb{D D}^{2,3}$ Ibrahim Alsaidan ${ }^{(\mathbb{D},}{ }^{2}$ \\ and Muhannad Alaraj $\mathbb{D}^{2}$ \\ ${ }^{1}$ Department of Electrical Engineering, Jamia Millia Islamia, New Delhi 110025, India \\ ${ }^{2}$ Department of Electrical Engineering, College of Engineering, Qassim University, Buraydah 52571, Qassim, Saudi Arabia \\ ${ }^{3}$ Department of Electrical Engineering, Delhi Technological University, Delhi 110042, India
}

Correspondence should be addressed to Arjun Baliyan; arjunbaliyaneee@gmail.com

Received 15 July 2020; Revised 10 January 2021; Accepted 15 February 2021; Published 28 February 2021

Academic Editor: Fotios Georgiades

Copyright ( $(2021$ Arjun Baliyan et al. This is an open access article distributed under the Creative Commons Attribution License, which permits unrestricted use, distribution, and reproduction in any medium, provided the original work is properly cited.

The quality of power that is degrading day by day is an important issue for all the consumers. The important factor for this is harmonics in the voltage and current waveforms which can be resolved by the use of hybrid series active power filter. The combination consists of a series active power filter and a shunt passive filter connected in parallel to the load. The method used in this paper is for the purpose of achieving good harmonic compensation and reduced total harmonic distortion for various types of nonlinear loads as per the standards of IEEE 519. The proposed HSAPF technique uses the synchronous reference frame method for generating the compensating signal with an intelligent PI controller that uses particle swarm optimization (PSO) technique to obtain the required gain values needed to improve the steady state response of the system. The concept of vigorous HSAPF has been authenticated through MATLAB simulation analysis, and the results obtained validate the accuracy of the method for the different load conditions.

\section{Introduction}

In the recent times, due to the increase in the power demand, the quality of the power supply has deteriorated drastically at a very rapid rate. The main reason behind this is the use of nonlinear loads in the system which injects harmonics in the system, and therefore, it not only distorts the current and voltage waveform but also leads to poor power factor of the supply system [1].

Hence, it is required to compensate these harmonics generated due to nonlinear loads in the system. Conventionally, only passive filters were used for harmonic mitigation because of the simple advantage that they were cost effective and reliable, but on the other side, many drawbacks such as resonance and mistuning lead to their discontinuity in the system $[2,3]$. These drawbacks were recently overcome by the use of shunt active power filters in the system which behaves as a current source and compensates the harmonics injected by the nonlinear loads in the system.
Active power filters inject the same harmonics in the system as that of load, but they are opposite in phase to the load harmonics.

However, they were not preferable in the large systems due to cost limitations, and hence, series active power filter came in the late $80 \mathrm{~s}$ as a possible solution to the existing APFs. The different combinations of these series and shunt active power filters have efficiently removed the harmonics in the source current as well as in the load voltage. However, they also have the demerit of being expensive and high inverter losses $[4,5]$. Consequently, to overcome all these drawbacks and to have better harmonic mitigation with reduced overall cost, a novel hybrid series active power filter along with the artificial neural network-based PI controller [6] is proposed in the paper. Out of the different combinations of the hybrid filters that are used in the literature [7-11], the HSAPF is the most promising one [12]. The other evolutionary algorithms such as genetic algorithm [13], bacterial foraging [14], artificial bee colony [15], and 
gravitational search [16] have also been recommended in the last decades, but particle swarm optimization with its simplicity has an edge over the existing techniques. The aim is to reduce the total harmonic distortion in both the load voltage as well as in the source current as per the IEEE standard 519. The first proposal was based on the instantaneous reactive power theory $[17,18]$. Here, in case of nonideal supply (if $V_{s h} \neq 0$ ), the product of voltage and current will generate an average component which is not detachable; therefore, to overcome such difficulty, harmonic mitigation using the synchronous reference method is proposed in $[19,20]$. This method requires the PLL block to keep the source voltage at the correct phase angle.

The paper is organized as follows. In Section 2, a brief description about the system topology, reference voltage generation technique, harmonic passive filter, and proposed PSO-based PI control strategy have been discussed. In Section 3 , experimental results obtained from simulation are described in detail, and Section 4, finally, concludes the paper.

\section{Description of System Topology}

Hybrid series active power filter with the proposed PI controller that has been used here is the combination of series active power filter and a passive filter connected in parallel to the load. Figure 1 shows the proposed architecture of the above combination. The passive filters that have been used here are used to filter out the $5^{\text {th }}$ and $7^{\text {th }}$ harmonic components along with a high pass filter tuned for a specific frequency. The series APF is a combination of full bridge PWM, a three phase LC filter, and a DC link capacitor. This DC link capacitor provides the reactive energy that is needed to eliminate the harmonics. The LC filter used is to eliminate the ripples from the generated voltage of the inverter. The series APF as the name suggests is connected in series with the load. The artificial neural network-based PI controller used here is for the purpose of improving the steady state response of the system.

2.1. Reference Generation Voltage Technique. The synchronous reference frame method or $d q$ method is used to transfer the load voltages from the stationary frame to the rotatory frame and is given as

$$
\left[\begin{array}{l}
V_{d} \\
V_{q}
\end{array}\right]=\frac{2}{3}\left[\begin{array}{ccc}
\cos \theta & \cos \left(\theta-\frac{2 \pi}{3}\right) & \cos \left(\theta+\frac{2 \pi}{3}\right) \\
\sin \theta & \sin \left(\theta-\frac{2 \pi}{3}\right) & \sin \left(\theta+\frac{2 \pi}{3}\right)
\end{array}\right]\left[\begin{array}{c}
V_{L A} \\
V_{L B} \\
V_{L C}
\end{array}\right]
$$

A PLL has been used to correct the source voltage phase angle which is very much needed for transformation. The $V_{d}$ and $V_{q}$ voltages obtained can be further divided into average and oscillating parts:

$$
\begin{aligned}
& V_{d}=\overline{V_{d}}+\widetilde{V_{d}}, \\
& V_{q}=\overline{V_{q}}+\widetilde{V_{q}},
\end{aligned}
$$

where the load voltages are denoted by $V_{L A}, V_{L B}$, and $V_{L C}$ which contain harmonic components in it. Furthermore, $d q$ components are passed from the low-pass filters to eliminate the DC components present in it, and we get the net harmonic contents. After that, by doing the inverse transformation, we can obtain the harmonic components present in the load voltages after the compensation of the passive power filter:

$$
\left[\begin{array}{c}
V_{L A H} \\
V_{L B H} \\
V_{L C H}
\end{array}\right]=\left[\begin{array}{cc}
\cos \theta & \sin \theta \\
\cos \left(\theta-\frac{2 \pi}{3}\right) & \sin \left(\theta-\frac{2 \pi}{3}\right) \\
\cos \left(\theta+\frac{2 \pi}{3}\right) & \sin \left(\theta+\frac{2 \pi}{3}\right)
\end{array}\right]\left[\begin{array}{c}
\widetilde{V_{d}} \\
\widetilde{V_{q}}
\end{array}\right] .
$$

The same procedure is followed to transfer the source current into the rotating frame which is described below:

$$
\left[\begin{array}{l}
I_{d} \\
I_{q}
\end{array}\right]=\frac{2}{3}\left[\begin{array}{ccc}
\cos \theta & \cos \left(\theta-\frac{2 \pi}{3}\right) & \cos \left(\theta+\frac{2 \pi}{3}\right) \\
\sin \theta & \sin \left(\theta-\frac{2 \pi}{3}\right) & \sin \left(\theta+\frac{2 \pi}{3}\right)
\end{array}\right]\left[\begin{array}{c}
I_{S A} \\
I_{S B} \\
I_{S C}
\end{array}\right] .
$$

In the same way, obtained components contain DC as well as AC quantities, and similarly, we will filter out the DC quantity by using the low-pass filter, so the left out is net harmonic content. Again, after doing the inverse transformation, we can obtain the harmonic content present in the source current described as

$$
\left[\begin{array}{c}
I_{S A H} \\
I_{L B H} \\
I_{S C H}
\end{array}\right]=\left[\begin{array}{cc}
\cos \theta & \sin \theta \\
\cos \left(\theta-\frac{2 \pi}{3}\right) & \sin \left(\theta-\frac{2 \pi}{3}\right) \\
\cos \left(\theta+\frac{2 \pi}{3}\right) & \sin \left(\theta+\frac{2 \pi}{3}\right)
\end{array}\right]\left[\begin{array}{c}
\tilde{I_{d}} \\
\widetilde{I_{q}}
\end{array}\right] .
$$

The compensating signal is obtained by the combination of load voltage and the source current which is shown in Figure 2. From this figure, the error between the reference voltage and DC link capacitor voltage of the inverter is fed to the PI controller block, and the output of it is then subtracted from the oscillatory component. The oscillatory component mentioned here is obtained from the output of the low pass filter. Since the extra fundamental components such as $\Delta V_{c a f}, \Delta V_{c b f}$, and $\Delta V_{c c f}$ also get added to the harmonic components, so the reference compensating voltage can be defined as

$$
\begin{gathered}
V_{c a}^{*}=K I_{s a h}-V_{L a h}+\Delta V_{c a f}, \\
V_{c b}^{*}=K I_{s b h}-V_{L b h}+\Delta V_{c b f}, \\
V_{c c}^{*}=K I_{s c h}-V_{L c h}+\Delta V_{c c f} .
\end{gathered}
$$




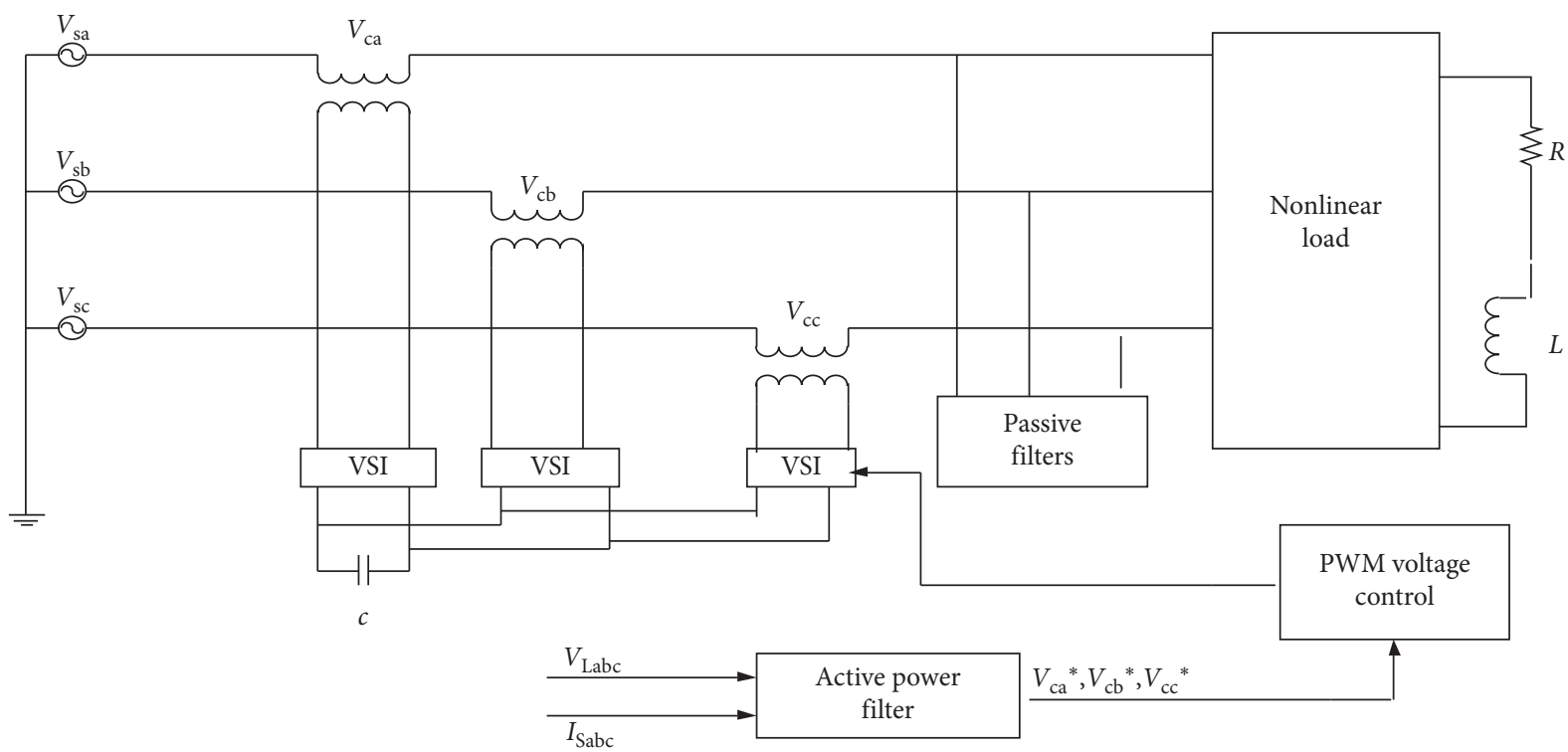

FIgURE 1: Hybrid series active power filter.

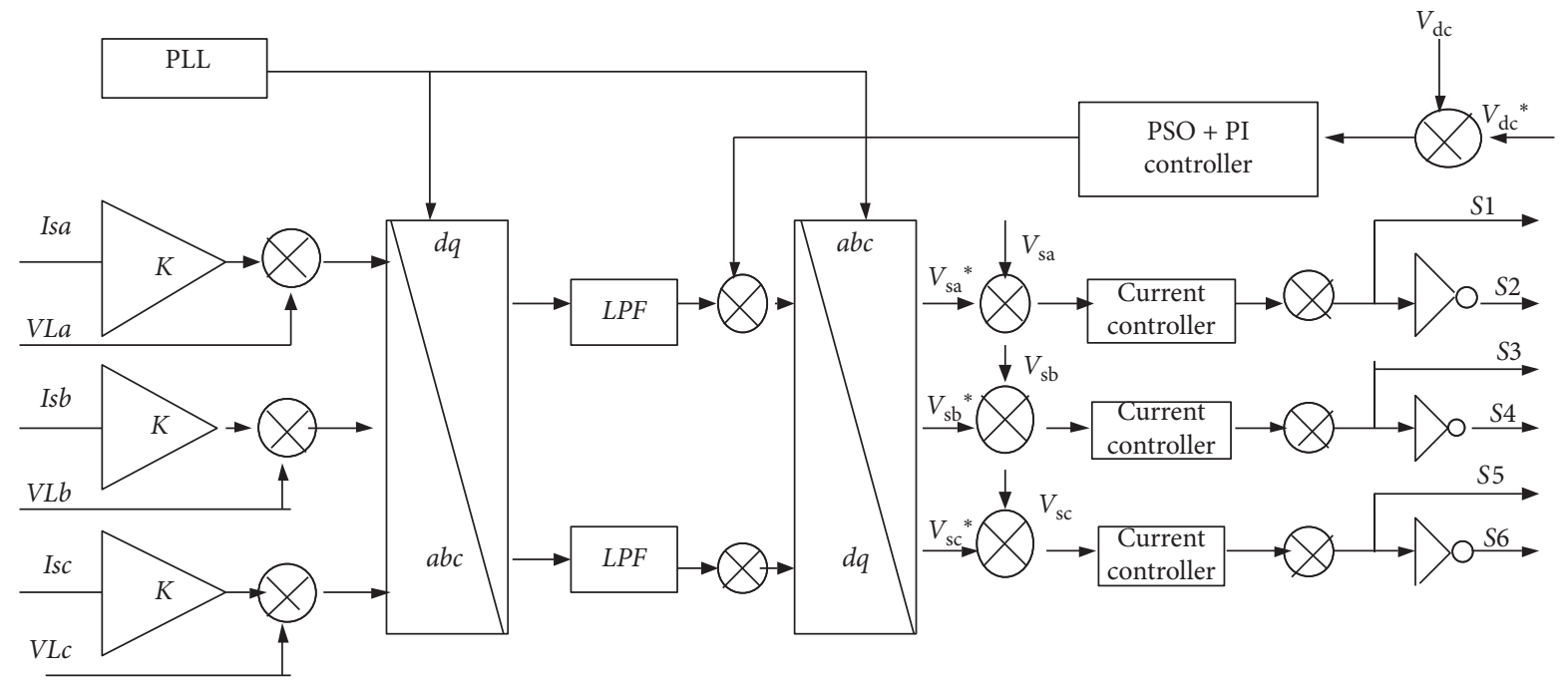

FIGURE 2: Block diagram for the proposed approach.

These currents $I_{s a h}, I_{s b h}$, and $I_{s c h}$ are basically defined as the harmonic components of the source current, whereas $V_{L a h}, V_{L b h}$, and $V_{L c h}$ are defined as the harmonic components of the load voltages.

2.2. Harmonic Passive Filter. These filters are used to enhance the quality of the voltage waveform by diverting the current other than the fundamental current or we can say the high frequency component current into the low impedance path. They are usually connected in shunt and also used to provide the reactive power requisite by the load for the purpose of power factor improvement.

In this system, we are using four harmonic passive filters in order to eliminate the $5,7,11$, and $13^{\text {th }}$ order harmonics. To remove the high frequency component, we are also using the high-pass branch in the circuit. Using the technique recommended in [21], we have calculated the value of elements $R, L$, and $C$ in such way that it optimizes the performance of the filter. Also, in order to remove the resonance problem, the filter is tuned at the frequency which is less than the harmonic frequency as we know most of the power system components are inductive in nature [22]. Figure 3 describes the passive harmonic filter, and Figure 4 represents the high pass filter or the damped filter.

2.3. Particle Swarm Optimization. In this paper, particle swarm optimization technique has been proposed to study the performance of the hybrid series active power filter. PSO is required here to obtain the optimal values of the gain constant that is required by the PI controller. The proposed algorithm updates the velocity and position of the particles till it reaches the desired objective. Each and every particle in 


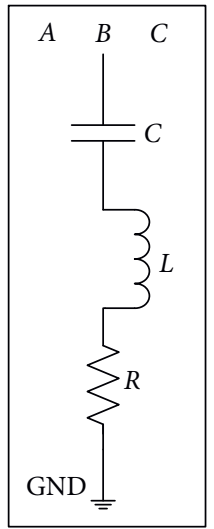

FIgURE 3: Harmonic passive filter.

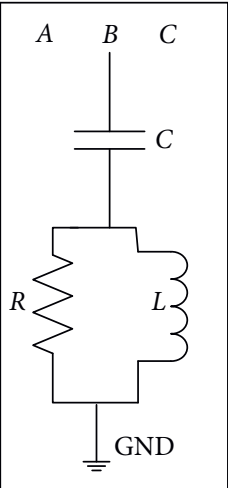

Figure 4: Damped filter.

the workspace is assigned with some arbitrary velocities. All particles search for optimal position in the global space by regularly updating their position and velocity. The particle optimizer checks for the best position attained so far [23]. Hence, based on the above concept tunes, the value of gain constant of the PI controller is such that the error between the $V_{\mathrm{dc}}$ and the reference voltage is minimized and it almost reaches the zero value.

The generalized equation for error can be given as

$$
\text { Error }=\text { Reference Voltage }-V_{\mathrm{dc}} \text {, }
$$

where $V_{\mathrm{dc}}$ is the DC link capacitor voltage.

The conventional PI controllers were not able to give the accurate results under unbalanced power supply voltage and also in case of severe load changing conditions. Hence, to overcome such issue, the PI controllers are tuned with different intelligent techniques to overcome the above existing issues. The output of the controller can be written as

$$
\text { Output }=K_{p} \cdot e(t)+K_{i} \int_{0}^{t} e(t) \mathrm{d} t .
$$

The PSO technique is widely used nowadays because of its simplicity, faster convergence rate, and greater accuracy. The DC link voltage has to be stabilized under severe load variations in the system. The tuning of PI controller parameters is a major challenge under the load changing conditions. Figure 5 represents the block diagram of the design of the PI controller using PSO.

\section{Simulation Results}

To examine the authenticity of the proposed controller, different types of loads have been taken for the purpose of analysis and are simulated in MATLAB using "Sims Power System Block set." The parameters taken are mentioned in Table 1. The aim of the simulation is to show the effectiveness of the proposed controller in reducing the THD of the system to a significant level. Figure 6 shows the circuit model for different loads taken for the analysis.

3.1. Case 1: Harmonic Compensation in Case of Battery Charger Load. The performance in this case is authenticated through a diode bridge rectifier with a battery charger load. It has been observed from the results that the THD of the load voltage has been reduced from $21.83 \%$ to $3.99 \%$ and THD in the source current is now reduced to $4.20 \%$ which justifies the IEEE standard 519. Figure 7 represents the steady state performance of source current $I_{s}$ and the load voltage $V_{L}$. Figures 8-10 show the FFT analysis of the both source current and the load voltage.

Figure 11 gives the DC link voltage in case of battery charger load.

3.2. Case 2: Harmonic Compensation in Case of RL Load. In this case, the diode bride rectifier with RL load has been taken to see the effect on the THD of the source current and the load voltage. Similarly, Figure 12 represents the source 


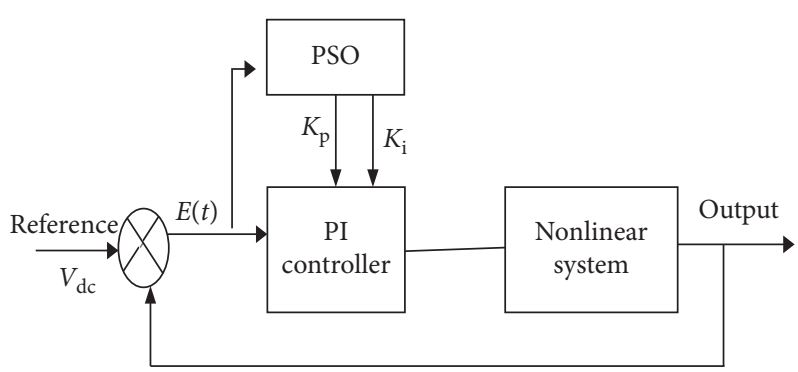

FIGURE 5: Block diagram representing the PI controller integrated with PSO.

TABLE 1: System parameters.

\begin{tabular}{lc}
\hline Parameters & Values \\
\hline Line voltage \& frequency & $V_{s}=220 \mathrm{~V}(\mathrm{RMS}), F_{s}=50 \mathrm{~Hz}$ \\
Line impedance & $L_{s}=0.5 \mathrm{mH}, R_{s}=0.1 \mathrm{ohm}$ \\
Nonlinear load & $L_{L}=30 \mathrm{mH}, R_{L}=25 \mathrm{ohm}, C_{L}=50 \mu \mathrm{F}$ \\
Battery charger load & $12 \mathrm{~V}, R_{L}=36.5 \mathrm{ohm}$ \\
Series active filter parameter & $C_{c}=60 \mu \mathrm{F}, L_{c}=1.35 \mathrm{mH}$ \\
Passive filter parameter & $C_{\mathrm{dc}}=1200 \mu \mathrm{F}, V_{\mathrm{dc}}=85 \mathrm{~V}$ \\
PI controller parameter & $L_{f}=1.86 \mathrm{mH}, C_{f}=60 \mu \mathrm{F}$ \\
$T_{s}$ and switching frequency & $K_{p}=1.816, K_{I}=1.1511$ \\
\hline
\end{tabular}

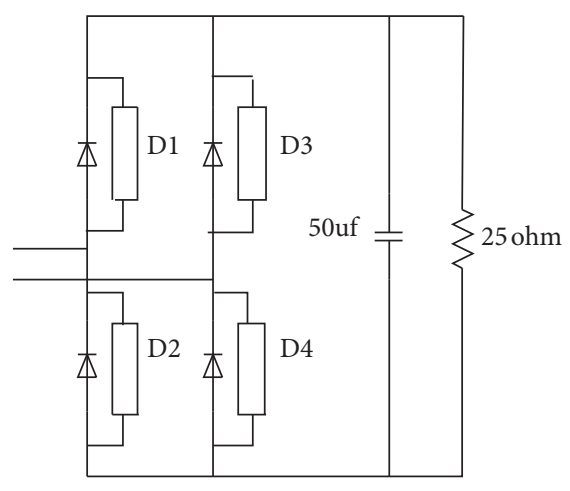

(a)

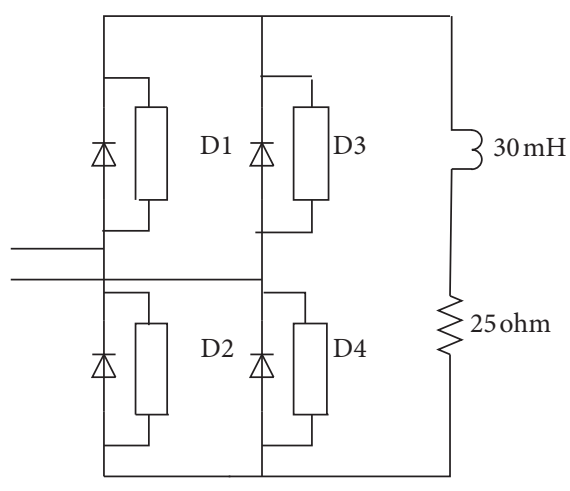

(b)

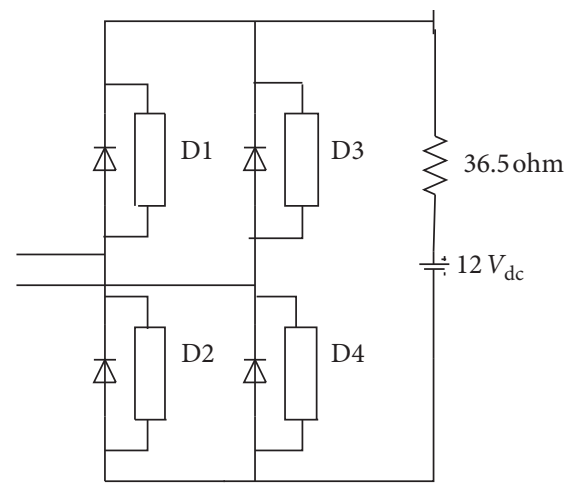

(c)

Figure 6: Different models of nonlinear loads: (a) RC load, (b) RL load, and (c) battery charger load.

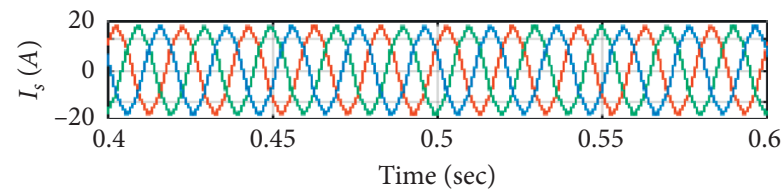

(a)

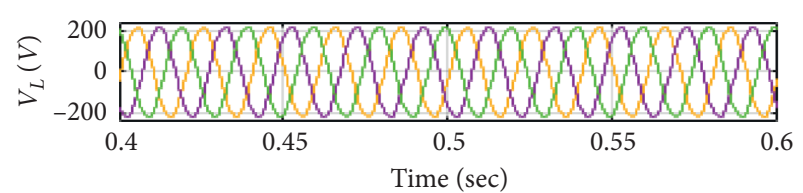

(b)

FIGURE 7: The steady state performance of (a) source current and (b) load voltage.

voltage, source current, and load voltage for this particular case. Finally, from Figures 13-15, we conclude that the THD of the source current has been reduced to $4.37 \%$ and the THD of the load voltage is reduced from $36.14 \%$ to $4.21 \%$ and both of them satisfy the IEEE standard 519. Figure 16 represents the error between the reference and the DC link voltage which is reduced to zero value.
3.3. Case 3: Harmonic Compensation in Case of Both Nonlinear Loads. In this case, the performance of HSAPF with the PI Controller for nonlinear load condition has been evaluated. Figure 17 shows steady state response of the supply current and the load voltage. The simulation results obtained as per Figures 18-20 show that the THD of the source current has been reduced to $4.54 \%$ and the THD of 


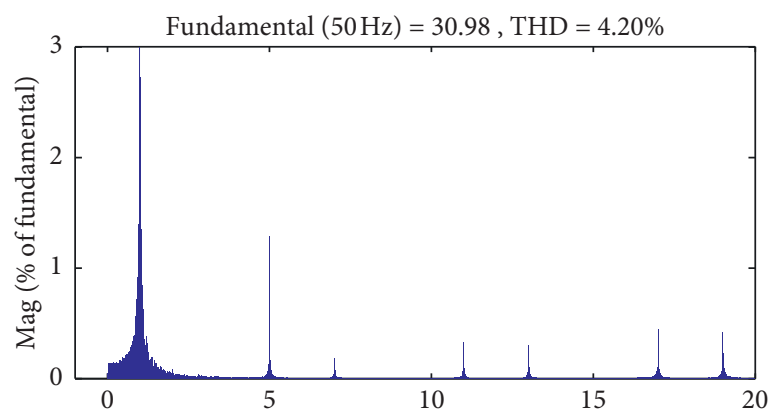

FIgURE 8: The THD in source current (after compensation).

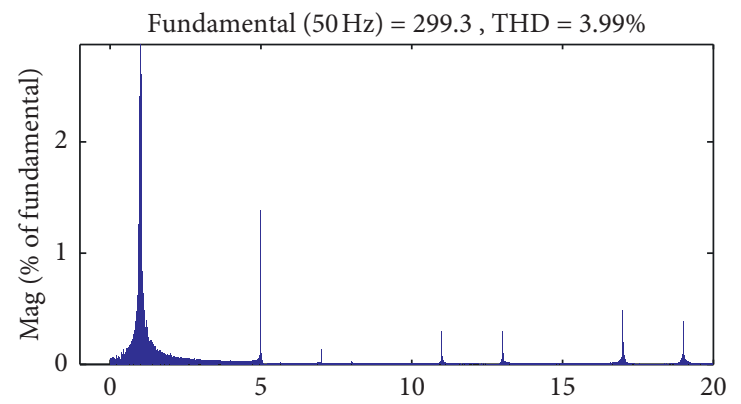

FIgURE 9: The THD in load voltage.

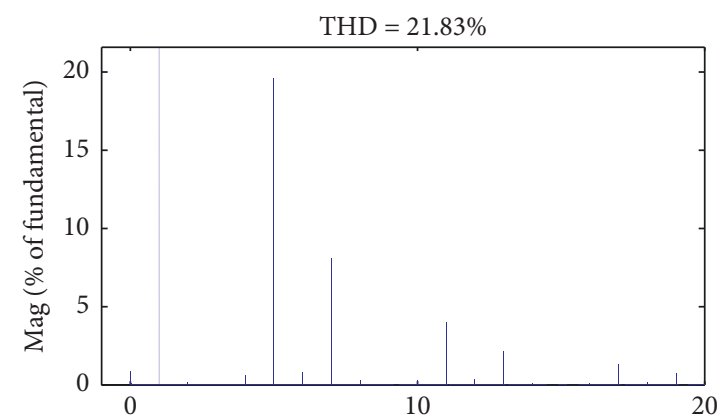

FIgURE 10: THD in load voltage (before compensation).

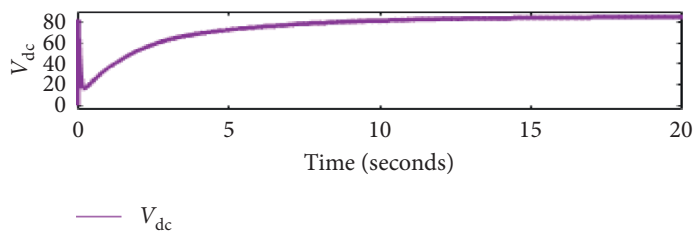

FIgURE 11: The DC link capacitor voltage. 


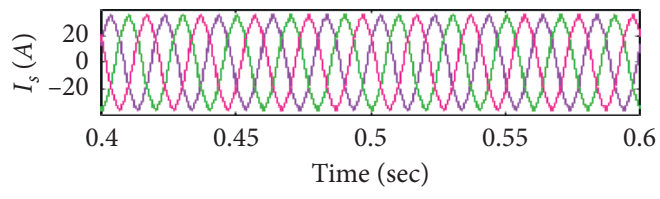

(a)

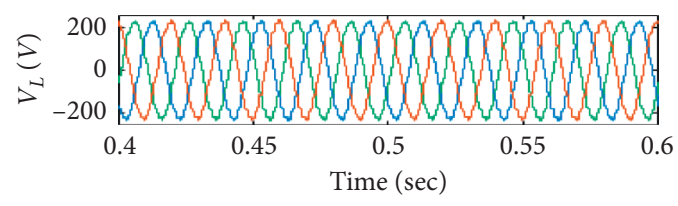

(b)

FIGURE 12: Steady state waveform of source current and the load voltage.

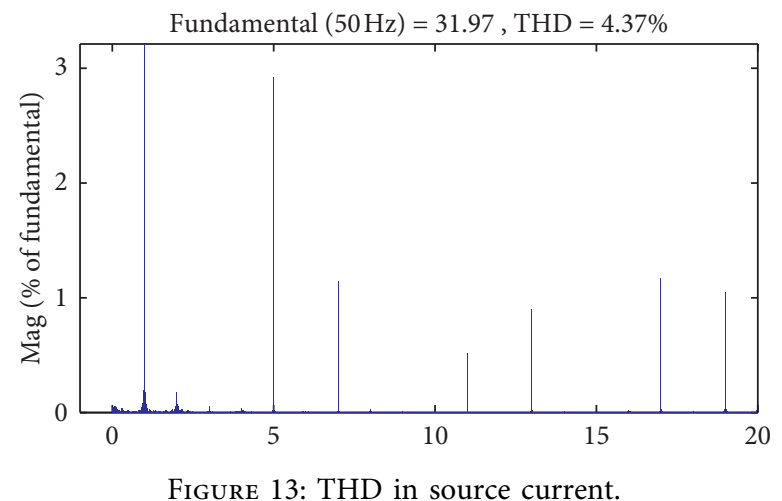

FIgURE 13: THD in source current.

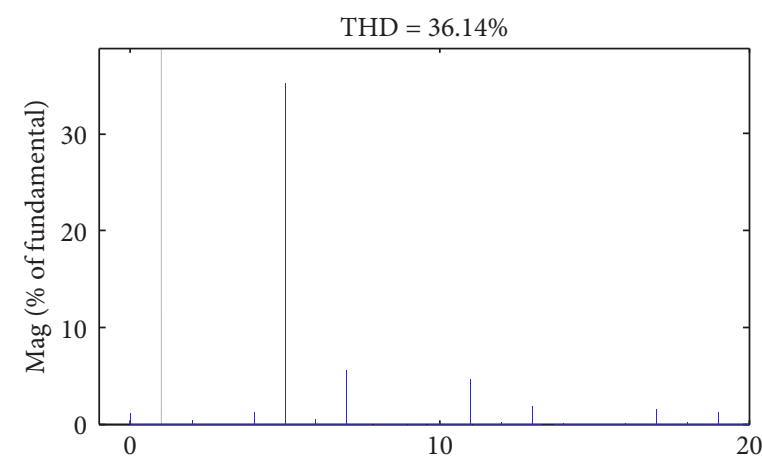

FIgURE 14: THD in load voltage (before compensation).

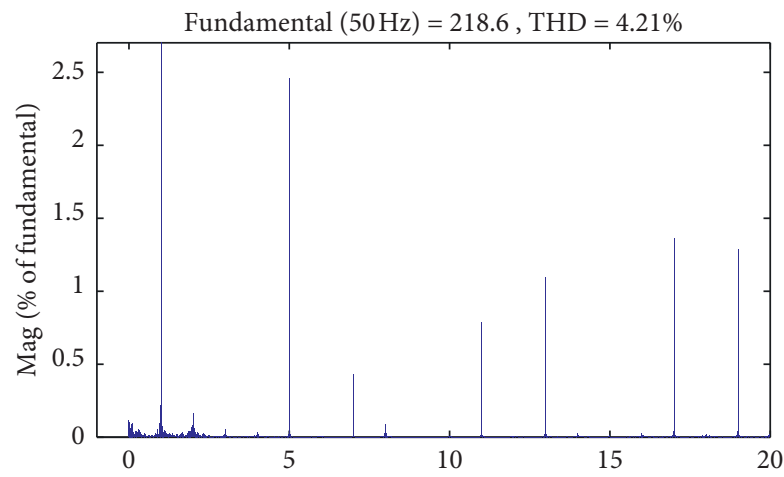

FIGURE 15: THD in load voltage (after compensation). 


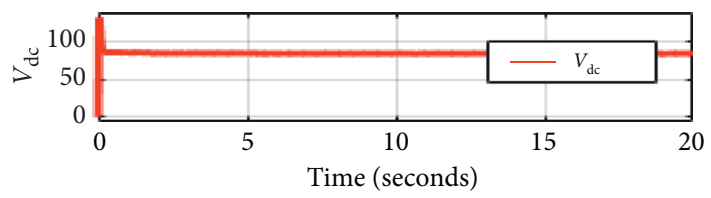

(a)

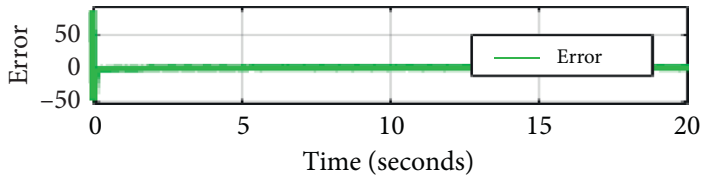

(b)

FIgURE 16: Capacitor DC link voltage and the error between $V_{\mathrm{dc}}$ and the reference voltage.

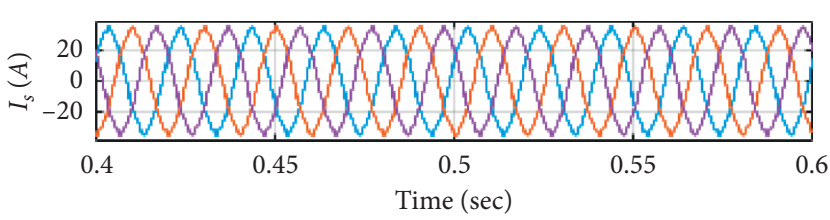

(a)

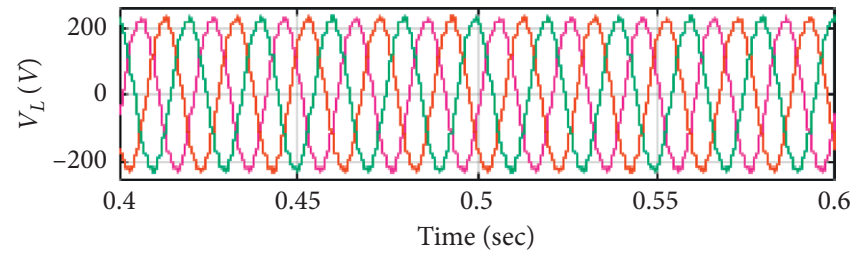

(b)

FIGURE 17: Steady state performance of (a) source current and (b) load voltage.

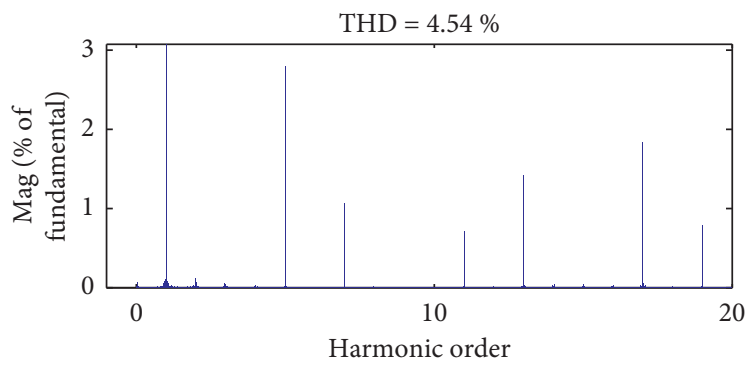

FIGURE 18: THD of source current (after compensation).

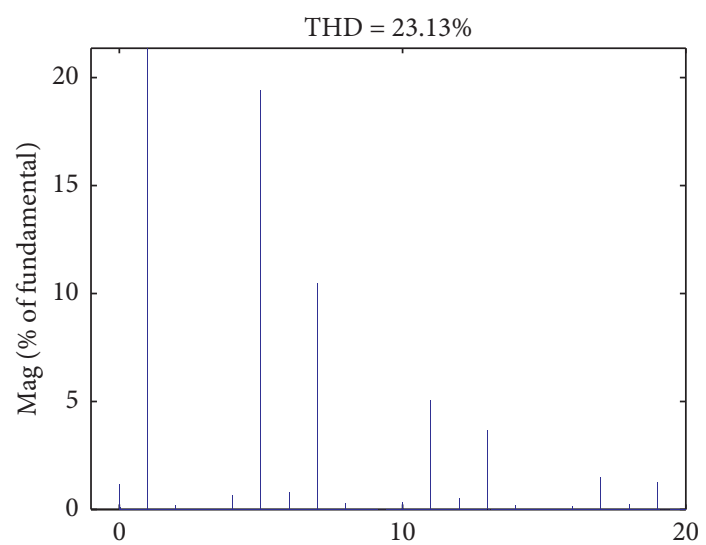

FIgURE 19: THD of load voltage (before compensation). 


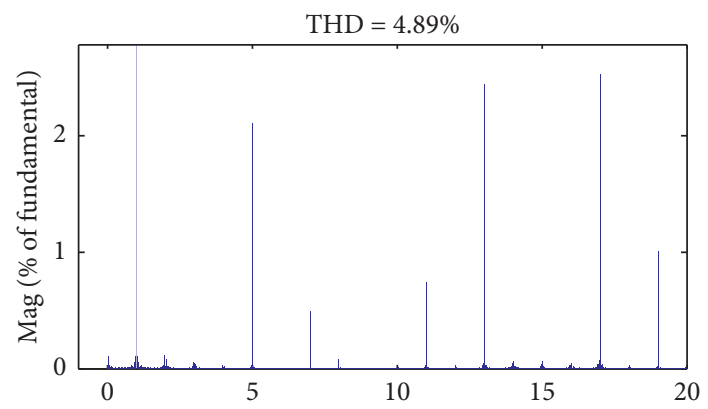

Figure 20: THD of load voltage (after compensation).

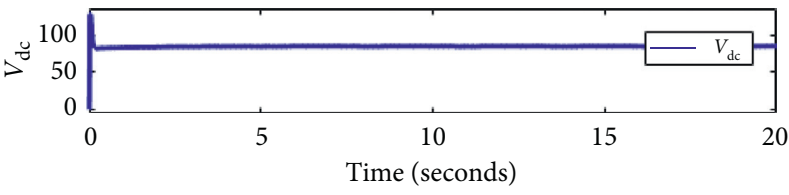

(a)

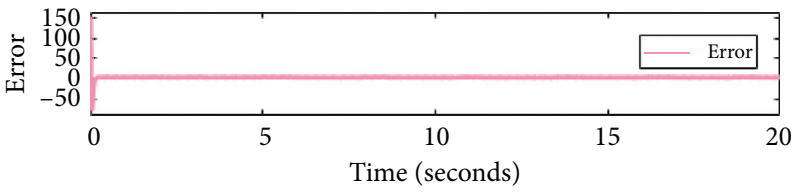

(b)

FIGURE 21: DC link voltage and the error between reference and the capacitor voltage.

TABLE 2: THD (\%) in different load conditions.

\begin{tabular}{lcc}
\hline Loads & THD (before compensation) (\%) & THD (after compensation) (\%) \\
\hline RL load & 36.14 & 4.21 \\
Battery charger load & 21.83 & 3.99 \\
(RC and RL) load & 23.13 & 4.89 \\
\hline
\end{tabular}

the load voltage is now $4.89 \%$. Figure 21 shows the accuracy of the DC link capacitor voltage since it is stabilized at the required reference level.

Hence, from the three cases presented for different load variations, it is clear that the proposed method has better results in comparison to the existing intelligent techniques. Table 2 summarizes THD in load voltage for the different cases discussed in the paper.

\section{Conclusion}

The performance of HSAPF with the PI controller integrated with PSO is evaluated, and it is found better as compared to the amalgamation of other hybrid technique that uses series passive filter and shunt active power filter scheme. The hybrid control scheme is basically the coalition of source current and the load voltage detection approach. The proposed technique successfully compensates the harmonics in the source current and the load voltage under different loading conditions such as RL, both in nonlinear load as well as in case of battery charger load. The simulation results in various cases prove that the THD is in accordance with the IEEE standard 519, i.e., less than 5\%. The proposed approach works well for different load variations in the system.

\section{Data Availability}

No data were used to support the findings of the study.

\section{Conflicts of Interest}

The authors declare that they have no conflicts of interest.

\section{References}

[1] Z. Zeng, H. Yang, S. Tang, and R. Zhao, “Objective-oriented power quality compensation of multifunctional grid-tied inverters and its application in microgrids," IEEE Transactions on Power Electronics, vol. 30, no. 3, pp. 1255-1265, 2015.

[2] H. Akagi and H. Fujita, "A new power line conditioner for harmonic compensation in power systems," IEEE Transactions on Power Delivery, vol. 10, no. 3, pp. 1570-1575, 1995.

[3] S. Rahmani, K. Al-Haddad, and F. Fnaiech, "Aseries hybrid power filter to compensate harmonic cureents and voltages," in Proceedings of the IEEE 2002 28th Annual Conference IECON 02 Industrial Electronics Society, pp. 644-649, Sevilla, Spain, November 2002.

[4] E. R. Ribeiro and I. Barbi, "Harmonic voltage reduction using a series active filter under different load conditionsfilter under different load conditions," IEEE Transactions on Power Electronics, vol. 21, no. 5, pp. 1394-1402, 2006.

[5] F. Z. Peng, H. Akagi, and A. Nabae, "A new approach to harmonic compensation in power systems-a combined system of shunt passive and series active filters," IEEE Transactions on Industry Applications, vol. 26, no. 6, pp. 983-990, 1990.

[6] S. Janpong, K. L. Areerak, and K. N. Areerak, "A literature survey of neural network applications for shunt active power filters," International Journal of Electrical and Computer Engineering, vol. 5, no. 12, 2011. 
[7] B. Singh, G. Bhuvaneswari, and S. R. Arya, "Review on power quality solution technology," Asian Power Electronics Journal, vol. 6, no. 2, 2012.

[8] C. Kumar and M. K. Mishra, "An improved hybrid DSTATCOM topology to compensate reactive and nonlinear loads," IEEE Transactions on Industrial Electronics, vol. 61, no. 12 , pp. 6517-6527, 2014

[9] T.-L. Lee, Y.-C. Wang, J.-C. Li, and J. M. Guerrero, "Hybrid active filter with variable conductance for harmonic resonance suppression in industrial power systems," IEEE Transactions on Industrial Electronics, vol. 62, no. 2, pp. 746-756, 2015.

[10] Y. Jiang, J. Chang, and S. Tian, "Multi-objective optimal design of hybrid active power filter," in Proceedings of the International Conference on Advanced Manufacture Technology and Industrial Application, Shanghai, China, September 2016.

[11] Z. Shuai, A. Luo, R. Fan, K. Zhou, and J. Tang, "Injection branch design of injection type hybrid active power filter," Automation of Electric Power Systems, vol. 31, no. 5, pp. $57-60+75,2007$.

[12] S. Bhattacharya and D. Divan, "Synchronous frame-based controller implementation for a hybrid series active filter system," in Proceedings of the Conference Record of the 1995 IEEE Industry Applications 30th IAS Annual Meeting, pp. 2531-2540, Orlando, FL, USA, October 1995.

[13] Q. Long, “A constraint handling technique for constrained multi-objective genetic algorithm," Swarm and Evolutionary Computation, vol. 15, pp. 66-79, 2014.

[14] T. Sudhakar Babu, K. Priya, D. Maheswaran, K. Sathish Kumar, and N. Rajasekar, "Selective voltage harmonic elimination in PWM inverter using bacterial foraging algorithm," Swarm and Evolutionary Computation, vol. 20, pp. 74-81, 2015.

[15] R. Akbari, R. Hedayatzadeh, K. Ziarati, and B. Hassanizadeh, "A multi-objective artificial bee colony algorithm," Swarm and Evolutionary Computation, vol. 2, pp. 39-52, 2012.

[16] E. Rashedi, E. Rashedi, and H. Nezamabadi-Pour, "A comprehensive survey on gravitational search algorithm," Swarm and Evolutionary Computation, vol. 41, 2018.

[17] L. Asiminoaei, E. Aeloiza, P. N. Enjeti, and F. Blaabjerg, "Shunt active-power-filter topology based on parallel interleaved inverters," IEEE Transactions on Industrial Electronics, vol. 55, no. 3, pp. 1175-1189, 2008.

[18] S. Rahmani, N. Mendalek, and K. Al-Haddad, "Experimental design of a nonlinear control technique for three-phase shunt active power filter," IEEE Transactions on Industrial Electronics, vol. 57, no. 10, pp. 3364-3375, 2010.

[19] S. Hirve, K. Chatterjee, B. G. Fernandes et al., "PLL-less active power filter based on one-cycle control for compensating unbalanced loads in three-phase four-wire system," IEEE Transactions on Power Delivery, vol. 22, no. 4, pp. 2457-2465, 2007.

[20] M. C. Benhabib and S. Saadate, "New control approach for four-wire active power filter based on the use of synchronous reference frame," Electric Power Systems Research, vol. 73, no. 3, pp. 353-362, 2005.

[21] W. M. Grady, M. J. Samotyj, and A. H. Noyola, "Survey of active power line conditioning methodologies," IEEE Transactions on Power Delivery, vol. 5, no. 3, pp. 1536-1542, 1990.

[22] B. Singh, A. Chandra, and K. Al-Haddad, "Computer-aided Modeling and simulation of active power filters," Electric Machines \& Power Systems, vol. 27, no. 11, pp. 1227-1241, 1999.
[23] S. S. Patnaik and A. K. Panda, "Real-time performance analysis and comparison of various control schemes for particle swarm optimization-based shunt active power filters," International Journal of Electrical Power \& Energy Systems, vol. 52, pp. 185-197, 2013. 